\title{
An Update on the Knowledge of Parasite-Vector Interactions of Chagas Disease
}

\author{
Günter A Schaub \\ Zoology/Parasitology, Ruhr-University \\ Bochum, Bochum, Germany
}

\begin{abstract}
This review focusses on the interactions between the etiologic agent of Chagas disease, Trypanosoma cruzi, and its triatomine vector. The flagellate mainly colonizes the intestinal tract of the insect. The effect of triatomines on trypanosomes is indicated by susceptibility and refractoriness phenomena that vary according to the combination of the strains. Other effects are apparent in the different regions of the gut. In the stomach, the majority of ingested blood trypomastigotes are killed while the remaining transform to round stages. In the small intestine, these develop into epimastigotes, the main replicative stage. In the rectum, the population density is the highest and is where the infectious stage develops, the metacyclic trypomastigote. In all regions of the gut, starvation and feeding of the triatomine affect $T$. cruzi. In the small intestine and rectum, starvation reduces the population density and more spheromastigotes develop. In the rectum, feeding after short-term starvation induces metacyclogenesis and after long-term starvation the development of specific cells, containing several nuclei, kinetoplasts and flagella. When considering the effects of T. cruzi on triatomines, the flagellate seems to be of low pathogenicity. However, during stressful periods, which are normal in natural populations, effects occur often on the behaviour, eg, in readiness to approach the host, the period of time before defecation, dispersal and aggregation. In nymphs, the duration of the different instars and the mortality rates increase, but this seems to be induced by repeated infections or blood quality by the feeding on infected hosts. Starvation resistance is often reduced by infection. Longevity and reproduction of adults is reduced, but only after infection with some strains of T. cruzi. Only components of the surface coat of blood trypomastigotes induce an immune reaction. However, this seems to act against gut bacteria and favours the development of T. cruzi.
\end{abstract}

Keywords: triatomines, Trypanosoma cruzi, behavior, immunity, fitness, reproduction

\section{Plain Language Summary}

This review focusses on the interactions between the etiologic agent of Chagas disease, Trypanosoma cruzi, and the vector, triatomines. This disease was once entirely confined to mainly rural Latin America with poor housing conditions, but in the last decades, emigrants brought it to a few other countries, eg, in Europe, but there is no endemic transmission outside the Americas. The flagellate mainly colonizes the intestinal tract of the blood-sucking insect. As in all parasite-vector systems, susceptibility and refractoriness phenomena are determined by the combination of the respective strains. The development in different regions of the gut is influenced by feeding and starvation of the triatomines, affecting not only population densities but also the development of specific stages of the flagellate. Considering the effects of $T$. cruzi on triatomines, the flagellate seems to be of low pathogenicity. However, during stressful periods, which are normal in natural populations, effects occur, often in the behaviour. In pre-adult stages, the nymphs, the duration of the
Correspondence: Günter A Schaub Zoology/Parasitology, Ruhr-University Bochum, 4480I Bochum, Germany Tel +492343224587

Fax +492343204587

Email guenter.schaub@rub.de 
different instars and the mortality rates increase, but mainly after feeding on infected hosts. Starvation resistance of nymphs is often reduced as the longevity and reproduction of adults, but only after infection with some strains of $T$. cruzi. Only components of the surface coat of blood trypomastigotes induce an immune reaction. However, this seems to act against gut bacteria and favours the development of T. cruzi.

\section{Introduction}

Chagas disease, also known as American trypanosomiasis, is caused by the protozoan parasite Trypanosoma cruzi (Chagas, 1909) (Kinetoplastida, Trypanosomatidae). It is the only important tropical disease in which the parasite has at first been detected in the vector, triatomines, and later on the infection of humans. ${ }^{1-3}$ In 1975/76, the World Health Organization classified it as one of the "Big Six" of tropical diseases and established a "Special Programme for Research and Training in Tropical Diseases". 4 After 2000, it has been included as one of about 17 "Neglected" diseases in "The Millennium Development Goals for Health - Rising to the Challenges". 5 All of these neglected diseases are of low priority to pharmaceutical companies regarding the development of new drugs and for government officials and public health programs. ${ }^{6}$ More than 110 years after the detection of $T$. cruzi, public health measures concerning Chagas disease are still lacking in many endemic areas. ${ }^{7}$ In Latin America, urbanization has induced the movement of infected rural populations to the cities. Once entirely confined to Latin America, Chagas disease has been spread widely by infected emigrants in the last decades and is now also present in the United States of America, Canada, many European countries and some African, Eastern Mediterranean and Western Pacific countries. ${ }^{8}$ However, vectorial transmission is limited to the Americas. According to actual estimations, 6 to 7 million people worldwide are infected with $T$. cruzi and 75 million people are at risk of infection. ${ }^{9}$

An infection in humans is possible if feces and/or urine of infected vectors gets into contact with the bite wound or other skin breaks or mucous membranes of the eyes or the lips (reviewed by ${ }^{10}$ ) An oral infection occurs after consumption of infectious meat or juices of fruits or sugar cane contaminated with remnants of triatomines. Transfusion of blood or organ transplantation from infected people is another source as is the transmission from mother to child. After the infection, amastigote stages of $T$. cruzi multiply intracellularly and before rupturing the host cell, they transform into nonreplicative blood trypomastigotes that infect new host cells or enter the blood capillaries and circulate in the blood. In the course of the disease two phases occur, the initial acute phase and the chronic phase (reviewed by ${ }^{10}$ ). In the acute phase, nonspecific symptoms develop, such as fever and a swelling of lymph nodes near the location of the infection. Usually, the parasite can be found in the blood. ${ }^{11}$ After about 1-2 months, the disease passes over to the chronic phase beginning with a latent phase, the indeterminate form, lasting from several years to decades with hardly any symptoms. ${ }^{10}$ Hardly any parasites are present in the blood. ${ }^{11}$ In the final chronic phase, the intracellular development and destruction of cells induces a dysfunction of organs. Large muscular hollow organs intestinal tract and heart - increase in diameter, a megaorgan syndrome. Especially, pathological effects in the heart may be lethal. ${ }^{10,12}$

Whereas the mammalian host provides cells for the intracellular development and constitutes a very stable environment in the blood offering glucose and a stable temperature, $\mathrm{pH}$, viscosity and osmolality to the blood trypomastigotes, the infection of a vector is a stressful event for $T$. cruzi. In the triatomine, the exclusive extracellular development is restricted to the lumen of the gut and the Malpighian tubules. ${ }^{13}$ In the stomach, glucose from the blood is only available for a short period of time, but proteins, amino acids and lipids must be used for metabolism. In addition, the $\mathrm{pH}$ becomes increasingly acidic. ${ }^{14}$ In this totally different environment, the blood trypomastigotes have to survive and differentiate (reviewed by ${ }^{15,16}$ ). They transform into spheromastigotes and epimastigotes, the latter multiplying more intensively than spheromastigotes. Finally, metacyclic trypomastigotes develop, possessing a kinetoplast in a more subterminal position than in blood trypomastigotes (reviewed by ${ }^{17}$ ).

\section{Trypanosoma cruzi: Taxonomy and Strain Peculiarities}

Trypanosoma cruzi is a protozoan hemoflagellate that multiplies by longitudinal divisions that result in a clonal genetic structure of the populations. Genetic recombinations are restricted but seem to occur. ${ }^{18}$ Initial groupings of the strains were based on isoenzyme patterns, but multilocus sequence typing separates six genetic subgroups (discrete typing units), named TcI-VI, plus two associated genotypes of bat trypanosomes. ${ }^{19}$ This grouping does not correlate with 
biological characteristics, eg, multiplication rates during in vitro cultivation or in the vector or mammalian hosts, and also virulence and pathogenicity for mammals and the development of infectious stages in the vector (reviewed by ${ }^{17}$ ). In Bolivia and Brazil, strains of all or nearly all typing units are present, but not all in other countries. A mixture of strains/clones can occur in the mammalian hosts or vectors $\left(\mathrm{eg},{ }^{20-22}\right)$. Analysing the geographical and host origin of discrete typing units of over 6000 strains, TcI is widely distributed geographically and predominates in sylvatic and domestic cycles, strains of $\mathrm{TcV}$ and $\mathrm{TcVI}$ in the latter. $^{23}$ The connection of some discrete typing units with humans and the domestic cycle or with wild mammals and sylvatic vectors cannot be generalized because presumably human migration and the change of many mammals between sylvatic and domestic habitats transfer strains to new regions. Wild marsupials often enter houses and are optimal reservoir hosts. ${ }^{24}$ After experimental infection, stages of $T$. cruzi that usually occur only in the vector develop in the anal scent glands of marsupials. ${ }^{25}$ During evolution, sylvatic mammals seem to be the primary hosts of T. cruzi, transmitting the parasite orally by carnivorous behaviour. Millions of years later, hematophagous triatomines evolved, and the dixenous life cycle of $T$. cruzi developed. ${ }^{25}$ Thereby, stages occurring in the scent glands of marsupials develop in the triatomines.

\section{Triatomines}

\section{Distribution of Triatomines}

Triatomines are the biggest blood-sucking insects and are predominantly found on the American continent from latitude $42^{\circ} \mathrm{N}$ to $46^{\circ} \mathrm{S}$, a region between the Great Lakes of North America and Argentina. ${ }^{26} \mathrm{~A}$ few species are present in Asia and Oceania, without a transmission of T. cruzi. ${ }^{27,28}$ Triatoma rubrofasciata (De Geer, 1773) is associated with rats in many tropical and subtropical harbours, also outside the Americas. ${ }^{29}$ The majority of the 150 recognized species live in sylvatic areas and are vectors in the sylvatic transmission cycle of T. cruzi. ${ }^{28,29}$ Other species live peridomestically and feed on domestic animals, eg, chicken and guinea pigs, but also invade houses. $^{30,31}$ Only some species are strictly adapted to houses and main vectors in the domestic cycle, eg, Triatoma infestans (Klug, 1834), Rhodnius prolixus Stål, 1859, Panstrongylus megistus (Burmeister, 1835) and Triatoma dimidiata (Latreille, 1811). ${ }^{30,31}$

\section{Digestion and Excretion of Triatomines}

All post-embryonic stages of all species of triatomines are obligatorily hematophagous, attacking all warm-blooded animals and ingesting about 6-12 times their own body weight. ${ }^{31}$ Such full engorgement or several smaller volumes of blood are required for the development to the next of the five pre-adult instars and oogenesis in females. ${ }^{31}$ In addition, mutualistic symbionts are required, at least during final nymphal instars and for oogenesis. ${ }^{32,33}$ So far, in only three species of triatomines the mutualistic symbionts have been identified, all Actinomycetales. ${ }^{32}$ After a full engorgement, triatomines can starve for up to 1 year, depending on the developmental stage. ${ }^{31}$ In particular, temperature and carbon dioxide in exhaled air attract triatomines, but also compounds simulating the human skin. ${ }^{34,35}$ Having approached the vertebrate host, they push the rostrum that protects the mouthparts onto the skin and the specifically interlocked maxillae penetrate the tissue by rapidly moving back and forth. ${ }^{36}$ The blood passes through the first region of the midgut, the cardia, and is stored in the following region of the midgut, the distensible stomach. There it remains mainly undigested, but ions and water are withdrawn, sugars resorbed and erythrocytes lysed. ${ }^{31}$ A most recent investigation indicates digestion processes in the stomach, ${ }^{37}$ but presumably serum proteins and not hemoglobin are digested. After the withdrawal of compounds without nutritional value, the concentrated blood possesses a jelly-like consistency, but after ingestion of blood from guinea pigs by $R$. prolixus the hemoglobin crystallizes. ${ }^{38,39}$ Small portions of blood are passed to the final region of the midgut, the small intestine, where the cells of the intestinal tract secrete extracellular membrane layers containing different glycoproteins and separating the intestinal content from the microvillar border of the cells. $^{40-42}$ There digestion of hemoglobin starts immediately, ${ }^{14,43-46}$ generating amino acids, including the amino acid tyrosine, but also free iron and heme that are toxic to triatomines. ${ }^{47,48}$ Whereas iron is absorbed and excreted, tyrosine and heme are metabolized, the latter to avoid the production of reactive oxygen species. ${ }^{47,48}$ Remnants of digestion are stored in the rectum before defecation. The rectal content contains different metabolites, eg, peptides, amino acids, fatty acids, steroids, glycerolipids, nucleotides and sugars. ${ }^{49}$

The increase in the size of the abdomen during blood ingestion is monitored by stretch receptors and induces the 
secretion of diuretic hormones and the activity of the most effective excretory system in the animal kingdom (reviewed by $^{31}$ ). Within 24 hours after blood ingestion, the excretion by the Malpighian tubules decreases the bug's body weight by about $40 \%$. Since the tubules end at the border to the rectum, the first urine sweeps out the dark remnants of digestion. Later yellow-white crystals follow and then new remnants of digestion (reviewed by ${ }^{50}$ ). During these phases of excretion, $\mathrm{pH}$, osmolality and the concentrations of the different ions change rapidly. ${ }^{51}$

\section{Immune System of Triatomines}

As in other animals, the immune system of triatomines consists of cellular and humoral components that respond to pathogens and parasites, ${ }^{52-54}$ also including behavioural fever responses. ${ }^{55}$ Cellular components have only been found in the hemolymph and not in any section of the intestine. If viruses, bacteria, fungi and parasites gain access to the intestine, the humoral immunity is activated via the immune deficiency (IMD), Toll and JAK-STAT pathways $^{52,56}$ that induce the production of different antimicrobial peptides (eg, lysozymes, defensins, prolixin, prophenoloxidase cascade), unidentified bacteriolytic compounds and antimicrobial molecules (eg, nitric oxide). ${ }^{57-59}$ The importance of the antimicrobial peptides is reflected by the high number of genes. In Triatoma pallidipennis Stål, 1872, 12 different genes encode for three defensins. ${ }^{60}$ Presumably as a possibility to reduce infections, in fifth instar nymphs of $T$. infestans antibacterial activities increase after feeding in the stomach and the small intestine, the latter possessing a much lower activity than the stomach, ${ }^{61}$ corresponding to the expression levels of genes encoding defensin and lysozyme ${ }^{62,63}$ and the prophenoloxidase activities in the Mexican T. pallidipennis. ${ }^{64}$

\section{Development of Trypanosoma cruzi in the Vector - Effects of the Vector}

The combination of the respective strain of $T$. cruzi and the species of the triatomine result in refractoriness or susceptibility phenomena of the vector. ${ }^{30}$ In many parasite-vector systems, eg, Plasmodium and mosquitoes, an infection induces anti-parasitic responses of the vector, affecting the success of the parasite for the establishment and the intensity of the parasitation. ${ }^{31}$ These aspects have only been considered in a low number of triatomine species using a low number of strains of T. cruzi (reviewed by $^{17,30}$ ).

\section{Development of $T$. cruzi in the Stomach}

During the initial period immediately after blood ingestion, different compounds from the triatomine are present in or secreted into the stomach. Agglutinins, hemolysins and anticoagulatory and antimicrobial compounds originate from the saliva of the triatomines and the wall of the stomach. ${ }^{52,65}$ Bacteria are also present in the saliva of triatomines ${ }^{66}$ and presumably ingested together with the blood and added to the intestinal bacteria. Effects on the trypanosomes have only been investigated for the salivary gland-secreted antimicrobial peptide trialysin, produced by T. infestans, which lyses blood trypomastigotes ${ }^{67}$ and is apparently neutralized by $T$. cruzi $^{\text {epimastigotes. }}{ }^{68}$ Agglutinins and hemolysins seem to determine the initial establishment of epimastigotes of $T$. cruzi in the vector (summarized by ${ }^{69}$ ) but blood trypomastigotes must be included in such investigations. None of these factors has been connected to the specific developmental steps of trypanosomes in the stomach.

According to the first detailed study of the morphological transformations of T. cruzi in the stomach of P. megistus, in the first days post-infection (pi) blood trypomastigotes and some intermediate forms occur. Later on, rounded parasites without changes indicating multiplications are present. ${ }^{70}$ Round and pear-shaped forms, aggregating a few days later, also develop in T. infestans and R. prolixus (eg, ${ }^{71,72}$ ). Finally, transitions to epimastigotes develop, elongated spheromastigotes.

In $R$. prolixus, the number of blood trypomastigotes of three strains/clones is strongly reduced within the first 24 hours pi ${ }^{73,74}$ and after 96 hours pi no parasites are found. ${ }^{74}$ According to qPCR, then only a few dozen parasites are present. ${ }^{73,74}$ The high mortality rate of blood trypomastigotes seems to be caused by compounds secreted into the stomach after blood feeding as indicated by in vitro incubations of blood trypomastigotes with extracts of the stomachs of either unfed or recent blood-fed R. prolixus. $^{74}$

The stomach is not totally hostile to epimastigotes. If after the molt the residues of the blood are passed to the small intestine, the colour of the intestinal contents becomes brownish and epimastigotes are present, presumably by a reflux from the small intestine. These epimastigotes survive or are killed after feeding on mice or hens, respectively. ${ }^{75}$

\section{Development of T. cruzi in the Small Intestine} After ingestion of infectious blood, epimastigotes develop only in the small intestine and rectum. There, spheromastigotes and especially epimastigotes multiply enormously. ${ }^{76}$ 
One week after an initial uptake of 8000 to 10,000 blood trypomastigotes/second instar nymph of $T$. infestans, there are about 30,000 parasites per small intestine. Using starvation periods of three or four weeks before blood-feeding the following instars and dissection of cohorts in weekly intervals, the number of trypanosomes is always slightly reduced before feeding, but increasing in each successive nymphal instar, up to a 20 -fold higher population density at 12 weeks pi. ${ }^{76}$

The flagellates are rarely in direct contact with the microvillar border of the cells of the intestinal wall, and more often they are present near the perimicrovillar membranes, which develop after blood ingestion and are reduced during starvation (reviewed by ${ }^{13}$ ). However, the development of $T$. cruzi is reduced by changing hormonal concentrations or feeding antibodies against perimicrovillar membranes. ${ }^{77-79}$ Presumably epimastigotes attach to the perimicrovillar membranes through different compounds, including cruzipain, heparin-binding molecules, cysteine peptidases and glycoinositol phospholipids $\left(\mathrm{eg},{ }^{80-83}\right)$. These membranes also contain many different glycoproteins, suggested to interact with the flagellate. ${ }^{42}$

\section{Development of $T$. cruzi in the Rectum}

The rectum contains the highest density of trypanosomes, in T. infestans about three times more than in the small intestine, although the volume and surface area are much smaller in the rectum. ${ }^{76}$ Presumably, one reason for the difference in population densities is the possibility of optimal attachment, and about $60 \%$ of the rectal trypanosome population is attached to the rectal cuticle. A small hydrophobic region on the flagellum of epimastigotes seems to bind to the wax layer that covers the whole rectal cuticle (reviewed by ${ }^{13}$ ). In transmission electron microscopy flagella are enlarged in the contact region and possess hemidesmosome-like material beneath the plasma membrane. ${ }^{84}$ Also, surface mucins of T. cruzi seem to be involved in the attachment, but Gp35/50 $\mathrm{kDa}$ mucins cover the whole body of the epimastigotes, not only the small hydrophobic region. ${ }^{85}$

Attachment is important for metacyclogenesis, ${ }^{86}$ presumably for at least one mode of metacyclogenesis, the unequal cell division of the epimastigotes, resulting in one daughter epimastigote and one daughter metacyclic trypomastigote, the latter possessing no properties for attachment by the short free flagellum and the thicker surface coat. Metacyclic trypomastigotes also develop from unattached long and short epimastigotes and spheromastigotes, as indicated by the translocation of the kinetoplast. ${ }^{76}$ Metacyclic trypomastigotes also occur in the small intestine, but mainly in the rectum. They possess a kinetoplast in a more subterminal position than in blood trypomastigotes. ${ }^{17}$ At two weeks pi $25 \%$ of the entire rectal population are trypomastigotes and from 10 weeks pi onwards it increases to $50 \%{ }^{76}$ In addition, after maintenance of infected $R$. prolixus at 26,28 and $30^{\circ} \mathrm{C}$, more metacyclic trypomastigotes are present at the latter temperature than at other temperatures. ${ }^{87}$

A clear effect of the vector on metacyclogenesis in the rectum is evident after blood ingestion by short-term starved nymphs. Within four hours, the proportion of slender intermediate stages increases significantly from $<7 \%$ to $10 \%$, but only of these intermediates between unattached epimastigotes and trypomastigotes. Although $\mathrm{pH}$, osmolarity and ion concentrations change drastically, the inducing factors are hemolymph proteins of about 17 $\mathrm{kDa}$ that pass into the rectum presumably via the Malpighian tubules at the beginning of diuresis. ${ }^{13,51,86}$ Another feeding-induced peculiar effect is evident after a long starvation period: One day after feeding, "giant cells" are present, ie, multiple cell division stages, containing several nuclei, kinetoplasts and flagella. Up to three days after blood-feeding, these "giant cells" represent on average 30 to $50 \%$ of the total parasite population. However, between 5 and 10 days after feeding they disappear, correlated with a strong increase in the rectal population density. ${ }^{88}$

In addition to feeding, starvation of the vector affects the rectal population. During starvation, the number of dead flagellates increases, but even then, all recta are colonized, sometimes restricted to the rectal pads (reviewed by ${ }^{13}$ ). Not only do population densities change but also the percentages of the different stages. ${ }^{89}$ At 20 days after blood-feeding, $2 \%$ and $1 \%$ of the population are either spheromastigotes or drop-like forms, ie intermediates between either sphero-, epi- or trypomastigotes, respectively. The percentage of spheromastigotes increases to about $20 \%$ after an additional 40 and 70 days.

\section{Effects of T. cruzi on Triatomines}

Since trypanosomes are classified as parasites, an infection with $T$. cruzi without any effect is improbable, but strong effects only occur regularly in infections of triatomines with other species of trypanosomatids (reviewed by ${ }^{90}$ ). We classify $T$. cruzi as weak pathogenic or subpathogenic, ie, pathologic effects only develop under adverse conditions 
by the presence of stressors, eg, starvation and missing mutualistic symbionts (reviewed by ${ }^{91}$ ). However, neither T. cruzi nor the vector are a homogenous group of organisms, and effects or missing effects should not be generalized for all T. cruzi-vector systems. The importance of the T. cruzi-strain is indicated by infections with different T. cruzi-strains which differently affect the same vector. $^{92,93}$

According to many investigations, T. cruzi affects the behaviour and the development of nymphs and adults, their physiology and life history traits (reviewed by $\left.{ }^{16,91,94-96}\right)$. However, investigations in the laboratory are affected by the choice of the system, the mode of maintenance of the triatomines and the supply with mutualistic symbionts. In addition, a very important aspect is the source of blood. The optimal system consists of colonies of triatomines which possess a nymphal mortality rate of $<10 \%$. The strains of $T$. cruzi should originate from the respective strain/species of triatomines, belong to different typing units and should be maintained by cyclical passages between vector and mammalian host or be stored frozen. Permanent passages between mice or in vitro cultivation should be avoided (Schaub unpublished). The colonies of triatomines should be maintained under optimal temperature, humidity and illumination conditions, choosing group sizes that exclude crowding stress. ${ }^{97}$ The presence of mutualistic symbionts in the nymphs is crucial and needs to be arranged. The development of the symbionts in the different regions of the intestine is regulated by the triatomines, resulting in high population densities in the stomach and very low numbers in the small intestine and rectum. ${ }^{98}$ When beginning with experimental groups of first instar nymphs, an addition of some males to the cohort provides the nymphs with the opportunity to acquire symbionts. In vitro culture-derived mutualistic symbionts can be given to experimental groups of nymphs after blood-feeding, but only in those species of triatomines, for which the mutualistic symbionts are known. ${ }^{32}$ Without the identification of the mutualistic symbiont, rectal bacteria originating from adult triatomines captured in the field can be cultured on agar plates. The supply of the experimental groups with a mixture of all slowgrowing actinomycetales avoids investigations of aposymbiotic bugs (Schaub unpublished). In aposymbiotic nymphs, a feeding on live hens and mice enables normal nymphal development. Artificial feeding devices using defibrinated or citrated blood of cows, sheep or humans usually affect the development of nymphs and adults
(Schaub unpublished). Only the use of defibrinated blood of pigs is optimal ${ }^{32}$ and equivalent to a feeding on live hosts. Also, in other laboratory investigations, the blood source affects the development of triatomines $\left(\mathrm{eg},{ }^{99-101}\right)$.

\section{Effects of $T$. cruzi on the Behaviour of Triatomines}

In the majority of the wide range of behaviours of triatomines (reviewed by ${ }^{102}$ ) the effects of the flagellate have not been investigated. Considering the attraction of triatomines by the host, blood-feeding and subsequent defecation results differ. No effects of $T$. cruzi are evident after experimental infection of $R$. prolixus and Triatoma rubrovaria (Blanchard, 1843): infected and uninfected individuals probe similarly frequently, require identical periods of times for feeding on live hosts, ingest similar volumes of blood and begin to defecate after identical periods of times. ${ }^{103,104}$

However, using second instar nymphs of Triatoma longipennis Usinger, 1939 and T. pallidipennis that were fed after the infection on uninfected mice, only third instar nymphs but not the following nymphal instars react more rapidly to human odor than uninfected nymphs. ${ }^{35}$ However, third instar nymphs are also more active than fifth instar nymphs indicating perhaps a more advanced physiological state of starvation. Also, long-term infected fifth instar nymphs of an indigenous species of Chile, Mepraia spinolai (Porter, 1934), starved for seven weeks after molting, orient themselves to the vertebrate host twice as fast as uninfected nymphs. ${ }^{105}$ In these infected nymphs, the number of probings is increased, and they begin to defecate earlier than uninfected bugs. The latter also occurs in fifth instar nymphs of $T$. infestans. ${ }^{106}$ Naturally infected $R$. prolixus nymphs feed less frequently than uninfected nymphs. Perhaps, the earlier defecation, the lower frequency of feeding and the lower volumes of ingested blood are induced by starvation: After long periods of starvation of 5-6 months, uninfected $R$. prolixus ingest lower volumes of blood but defecate earlier than bugs fasted for 2-3 months. ${ }^{103}$

An earlier defecation increases the transmission risk, but defecation behaviour differs between species and developmental stages, eg, in Triatoma rubida (Uhler, 1894). ${ }^{107}$ The earlier approach to the host seems to be without an effect on the transmission rate considering the usual single feeding per nymphal instar. It also remains to be investigated whether or not the earlier approach is an 
effect of the study design. If $T$. cruzi and the vector compete for nutritional resources, then infected nymphs may possess a more advanced state of starvation in comparison to uninfected nymphs of the identical age. The hypothesis that the behavioral changes observed can be related to a reduction in essential components of the blood is supported by a field study, in which infected $M$. spinolai possess a lower standardized body mass index than uninfected ones, and in which more $T$. cruzi-infected bugs are captured within the first hour of exposition of humans as hosts. $^{108}$

There are several investigations considering effects on locomotion. A competition for nutritional resources seems to have reduced the locomotion of infected fifth instars of $R$. prolixus by $20 \%$ as compared to uninfected individuals. ${ }^{109}$ About 8-12 days after infection of adult Rhodnius pallescens Barber, 1932 using a mixture of epimastigotes and blood, the infected females fly faster than infected males in a flight mill. ${ }^{110}$ Although T. cruziinfected males and females collected in the field have larger wings than uninfected individuals, ${ }^{111}$ the dispersal capabilities of females of $T$. dimidiata are increased by an infection, but similar in $T$. cruzi-infected and uninfected males. ${ }^{112}$ One possibility is that females include nutrients in the eggs that are deposited resulting in a lower weight and nutritional status of infected females than of infected males. In T. infestans, especially starvation increases flight initiation. ${ }^{113}$ In the laboratory, levels of negative geotaxis and aggregation are higher in both female and male adults of $T$. infestans infected with $T$. cruzi. ${ }^{114}$ Comparing the ecological niches of seven Mexican triatomine species, the ecological niche used by $T$. cruzi-infected populations is often reduced in comparison to uninfected populations, perhaps caused by an effect of T. cruzi on insect fitness. ${ }^{115}$

\section{Effects of T. cruzi on Nymphs of Triatomines}

Considering the effects of $T$. cruzi on nymphs, the results differ. The developmental time of individually maintained first instar nymphs increases fivefold and T. cruzi retards also the development of older infected nymphs of T. infestans. ${ }^{116}$ Retardations are also evident in $M$. spinolai, after blood-feeding on $T$. cruzi-infected mice, and nymphs are significantly lighter than controls. In addition, the mortality rate of fourth and fifth instar nymphs of $M$. spinolai is increased compared to uninfected nymphs. ${ }^{117,118}$ However, after blood-feeding on
T. cruzi-infected mice, the period of time until molting of first instar nymphs of Triatoma brasiliensis Neiva, 1911 is increased, but development and mortality rates of older nymphs are unaffected. ${ }^{119}$ The difference between both systems is a feeding of the older instar nymphs of M. spinolai on infected mice and of $T$. brasiliensis on uninfected mice. Perhaps repeated infections strongly increase the population density of the flagellate in the vector or $T$. cruzi affects the nutritive value and/or on the concentration of essential unknown compounds of the blood of infected mice. This can be compensated by either increasing the number of blood-feeds and/or the volume of blood ingested: Infected nymphs of $T$. rubrovaria, ingest significantly more blood than uninfected nymphs. ${ }^{104}$ The indication to the population density or the quality of blood is supported by the normal development of nymphs of T. infestans after infection via mice and subsequent feedings on uninfected mice or hens. ${ }^{120-122}$ The mortality rates of these nymphs of $T$. infestans are in the normal range and also the nymphal development of $P$. megistus and T. brasiliensis. ${ }^{119,123}$ Temperature modifies the effects: after a single feeding of second instar nymphs of $R$. prolixus via an artificial feeder with a mixture of human blood and epimastigotes and a maintenance between 21 and $30^{\circ} \mathrm{C}$, the molts of infected second instar nymphs are strongly delayed by 6-11 days. ${ }^{124}$ Whereas, at 90 days pi, the starvation induced mortality rate is high and similar in uninfected and infected groups maintained at 21 and $30^{\circ} \mathrm{C}$, it is significantly increased by the infection at 24 and $27^{\circ} \mathrm{C}$, temperatures at which $R$. prolixus is found in the wild. ${ }^{100,124}$

Not only do temperatures vary in the field but also the availabilities of hosts. During monitorings in the field, high percentages of starved individuals are common. $^{125,126}$ The data regarding whether or not the starvation capacity is affected by the infection differ. The period of time before the death of either third and fourth instar nymphs or adults of $M$. spinolai from the field is unaffected by the infection after feeding two times on uninfected mice before starvation. ${ }^{127}$ However, after an infection of fifth instar nymphs of $T$. pallidipennis, the starvation capacity is reduced. ${ }^{64}$ In experimental infections of first instar nymphs of $T$. infestans, followed by either one, two or three additional uninfected blood feedings to the subsequent nymphal instars on hens, the mean periods of survival of the resulting fourth and fifth instar nymphs are, respectively, 14 and $17 \%$ significantly shorter than those of uninfected nymphs. ${ }^{128}$ Death is not caused by 
a depletion of hemoglobin because more infected than uninfected nymphs contain the brown hemoglobin remnants of the blood in their small intestines. Therefore, T. cruzi and its vector seem to compete for essential metabolites whose depletion results in death. Since many trypanosomes die from starved nymphs, an accumulation of toxic products by $T$. cruzi seems unlikely. ${ }^{13}$

\section{Effects of T. cruzi on Adults of Triatomines}

Similar to nymphs, investigations of adults also show contradictory results considering fecundity and longevity. In M. spinolai fed on T. cruzi-infected mice, the weight of the gonads and the body size is reduced in comparison to females fed on uninfected mice, ${ }^{117}$ perhaps due to differences in the population densities or the quality of blood. This is also possible in four groupings of infected and uninfected females and males, in which uninfected females produced more and heavier eggs independently of the infection status of the males. ${ }^{129}$ In $T$. infestans fed on hens, the infection seems to reduce slightly both the egglaying rate during the first weeks of oviposition and the hatching rate. ${ }^{130}$ After an in vitro infection of second instar nymphs of $R$. prolixus with epimastigotes, the period of time before the first egg laying is similar in infected and uninfected females. ${ }^{131}$ Comparing a maintenance at $25^{\circ} \mathrm{C}$ and $30^{\circ} \mathrm{C}$, the latter decreases the fecundity of infected females in the first reproductive cycle and significantly fewer nymphs hatch from eggs laid in the third reproductive cycle. ${ }^{131}$ Also, infected couples of P. megistus, infected in the first instar on mice and fed in the following instars on defibrinated sheep blood, produce less eggs, fertile eggs and resulting nymphs. ${ }^{123}$ Similar effects are evident after infection of fifth instar nymphs of T. pallidipennis on mice and a subsequent feeding on uninfected mice. ${ }^{93}$ In $T$. infestans spermatogenesis is similar in uninfected and infected males. ${ }^{132}$ The importance of the respective strain of $T$. cruzi is highlighted after an infection of Colombian $R$. prolixus fifth instar nymphs with five different Colombian TcI strains and subsequent feedings on hens. ${ }^{92}$ In a comparison to uninfected adults, some $T$. cruzi strains significantly reduce survival while others have no effect. ${ }^{92}$ The reproduction is also reduced by one of these strains. ${ }^{133}$ Also, in Triatoma sp. and $R$. prolixus, the longevity of $T$. cruzi-infected adults is reduced, ${ }^{134,135}$ in the latter even more after feeding on T. cruzi-infected guinea pigs compared to groups fed on uninfected guinea pigs. After feeding on uninfected hosts, no effects of $T$. cruzi infection are evident on the mean lifespan of both adult males and females of $T$. brasiliensis and $T$. dimidiata, as well as the hatching rate of eggs, the period of time before oviposition, the number of ovipositions, and both the total number of eggs laid and number of fertile eggs. ${ }^{119,136}$

\section{Effects of T. cruzi on Immunity Responses of Triatomines}

In addition to access of bacteria, ingestion of $T$. cruzi induces an immune response, not only in the intestine but also synergistically in the hemolymph and other organs $\left(\right.$ summarized by ${ }^{90}$ ). A methodological problem is the use of the whole intestinal tract because the immune reactions in different regions differ strongly (see above). In addition, investigations using a mixture of epimastigotes and blood do not reflect the natural conditions. Epimastigotes are only ingested during coprophagy and then after blood ingestion, avoiding contact of fecal material with the blood. ${ }^{16}$ Describing the long-term effects of $T$. cruzi on the immunity, such investigations can be considered. The importance of the respective stage is indicated by the comparison of infections with epimastigotes and blood trypomastigotes. ${ }^{137}$ The surface of the latter is highly organized and contains lipid-driven domains with different protein compositions $\left(\mathrm{eg},{ }^{138}\right)$. Shedding of the surface coat of blood trypomastigotes can be induced by strong centrifugation forces and incubation in a protein-free buffer, ${ }^{139}$ as well as during a forced passage through a fine (ie, high gauge) syringe needle, increasing the shearing forces. After feeding fifth instar nymphs of T. infestans on T. cruzi-infected rats or a mixture of complement-inactivated rat blood with epimastigotes, the separated surface coat of the blood trypomastigotes and the resulting "naked" trypomastigotes, up to 5 days after feeding, antibacterial activity is significantly increased in the small intestine of nymphs that ingested either separated surface coats or intact blood trypomastigotes, but not "naked" trypomastigotes or in vitro culturederived epimastigotes. ${ }^{137}$

Several investigations report the effects of $T$. cruzi on antimicrobial peptides. Using the whole intestine of R. prolixus, at 7 and 14 days pi with blood trypomastigotes, the expression of a gene of the most intestinally active lysozyme is increased $>20$-fold. ${ }^{140}$ At 20 days pi with epimastigotes, in the small intestine of $T$. brasiliensis, the expression of the gene encoding a defensin is nearly 10 -fold higher than in uninfected nymphs. ${ }^{141}$ In the stomach of T. infestans at 24 hours pi on infected mice, the 
expression of genes encoding lysozyme, cathepsin D, a nitrophorin-like protein and a putative $14 \mathrm{kDa}$ protein are all significantly upregulated, while the gene encoding thioredoxin reductase is downregulated. Expression of genes encoding infestin, lipocalins, and defensins are unchanged. ${ }^{142}$ The activity of cathepsin $\mathrm{D}$ is higher in the small intestine of $R$. prolixus at 1 day and 3 days pi with epimastigotes, ${ }^{143}$ and a synergistic activity with lysozyme in the degradation of intestinal bacteria is discussed. ${ }^{14}$ Expression of the gene that encodes a cysteine protease inhibitor and perhaps acting against the enzyme of $T$. cruzi is significantly higher than in uninfected adults of $T$. infestans. ${ }^{144}$

Not only is the production of antimicrobial peptides and enzymes induced but also that of other antimicrobial compounds. Investigating one of these, nitric oxides, the concentrations cannot be determined directly, only via its metabolites, nitrite and nitrate. In $R$. prolixus, at 1 and 2 days pi concentrations of nitrite are higher than in uninfected blood-fed controls in both midgut regions. ${ }^{145}$ However, it is also increased in the stomach at 2 weeks pi, although no parasites are present there, and in the rectum, even before the parasites have passed to this region. ${ }^{145}$ Compared to uninfected blood-fed controls, the expression of the gene encoding nitric oxide synthase increases in the stomach at 1 day or 2 days pi when the development of $T$. cruzi is confined to this region. In the stomach of T. pallidipennis, the activities of prophenoloxidases are significantly higher in infected fifth instar nymphs at 28 days pi, while those of phenoloxidases are significantly lower at 9 days pi. ${ }^{146}$ In this system, the increase in prophenoloxidase activity is evident at 15 days pi and at $20^{\circ} \mathrm{C}$, but not at $30^{\circ} \mathrm{C}$ and $34^{\circ} \mathrm{C}^{64}$

The initial induction of these immune reactions seems to be without adverse effects on T. cruzi. However, after knockdown of antibacterial proteins, more bacteria are present in the stomach and the number of trypanosomes is significantly lower than in controls without a silencing of the antimicrobial proteins. ${ }^{147-149}$ Therefore, a shortterm upregulation of immune proteins by blood trypomastigotes suppresses the development of the bacteria. ${ }^{147-151}$ However, in long-term infections, T. cruzi seems to induce an immune suppression in the intestine. After feeding third instar nymphs with a mixture of blood trypomastigotes and different microorganisms, high numbers of fungi and bacteria are present only in $T$. cruzi-infected fifth instar nymphs, but not in uninfected controls. ${ }^{98}$

\section{Conclusions and Open Questions}

There are many reports on the effects of the vector on T. cruzi and vice versa. However, in some of them the effects seem to be caused by infections with attenuated strains of T. cruzi or by a sub-optimal maintenance of triatomines. In optimal systems both components originate from the same locality. Thereby, the virulence of different strains of $T$. cruzi can be compared. ${ }^{152}$ In optimal colonies of the triatomines, the access to mutualistic symbionts is supported. However, these symbionts must be identified in the majority of species of triatomines and also the function of the microbiota. ${ }^{153}$

Focussing on the development of $T$. cruzi in the different regions of the triatomine intestine, some interesting questions still require further investigation. Regarding the development of $T$. cruzi in the stomach, the use of optimal parasite-vector systems might clarify whether or not the initial death of the majority of blood trypomastigotes can be generalized for all species of triatomines and all lineages of $T$. cruzi. With regard to the population in the rectum, the molecules of the hydrophobic attachment zone of the flagellum of epimastigotes remain to be identified. Metacyclogenesis is another fascinating phenomenon investigated in detail using in vitro cultures $\left(\mathrm{eg},{ }^{154}\right)$. However, determination of the concentrations of oxygen and free amino acids and the pattern of lipids and proteins/peptides is required to compare them with the factors inducing metacyclogenesis in vitro. Investigations of the effects of $T$. cruzi on the vector must avoid stress conditions and use blood trypomastigotes. Considering the interesting T. cruzi-induced manipulation of the microbiome of triatomines by the induction of immune reactions, different lineages of T. cruzi should be used and the population densities of the respective bacteria should be determined, considering also the mutualistic symbiont of the respective species. The available genomic and proteomic data of triatomines, symbionts and T. cruzl ${ }^{46,155-159}$ can be connected to gain insight into the molecular base of the interactions and to find new potential targets for vector control.

\section{Abbreviations}

pi, post infection.

\section{Ethics Approval and Informed Consent}

The author reports no relevance.

\section{Consent for Publication}

The author reports no relevance. 


\section{Acknowledgments}

The author acknowledges the contributions of unknown reviewers and of many colleagues, who supplied him with pdfs of most recent publications and book contributions in press.

\section{Authors' Information}

I am engaged in investigations of $T$. cruzi and triatomines since 1978. I apologize if my emphasis on using optimal systems in such investigations seems to be too restrictive to colleagues with whom I have shared so many discussions, especially in Brazil. However, only then, a transfer to natural systems is possible. Administrative regulations against the feeding of triatomines on living animals and against the infection of laboratory mammals with $T$. cruzi reduce the quality of such investigations and the chance to attack the etiologic agent of this "neglected" disease.

\section{Funding}

The author is deeply grateful for the funding of the investigations and travels by the UNDP/World Bank/WHO Special Programme for Research and Training in Tropical Diseases, the Volkswagenstiftung, the German Academic Exchange Service (DAAD), European Community programmes, the Humboldt Foundation and especially the Deutsche Forschungsgemeinschaft.

\section{Disclosure}

The author declares no financial or non-financial competing interests.

\section{References}

1. Chagas C. Nova tripanozomiaze humana: estudos sobre a morfolojia e o ciclo evolutivo do Schizotrypanum cruzi n. gen., n. sp., ajente etiolojico de nova entidade morbida do homem. Mem Inst Oswaldo Cruz. 1909;1(2):159-218. doi:10.1590/S0074-02761909000200008

2. Schaub GA, Mehlhorn H. Kissing bugs. In: Mehlhorn H, editor. Encyclopedia of Parasitology. 4th ed. Berlin: Springer; 2016:14 00-1403.

3. de Araujo-Jorge T, Telleria J, Rios-Dalenz J. History of the discovery of the American Trypanosomiasis (Chagas disease). In: Telleria J, Tibayrenc M, editors. American Trypanosomiasis Chagas Disease. 2nd ed. Amsterdam: Elsevier; 2017:1-22.

4. Schaub GA, Wülker W. Tropische Parasitosen im Programm der Weltgesundheitsorganisation [Tropical parasitoses in the program of the World Health Organization]. Universitas. 1984;39:71-80.

5. Wagstaff A, Claeson M The millennium development goals for health rising to the challenges. 2004. Available from: http://www-wds.world bank.org/servlet/WDSContentServer/WDSP/IB/2004/07/15/ $000009486220040715130626 / \mathrm{Rendered/PDF/}$ 296730PAPER0Milent0goals0for0health.pdf. Accessed December 12, 2020.
6. Ehrenberg JP, Ault SK. Neglected diseases of neglected populations: thinking to reshape the determinants of health in Latin America and the Caribbean. BMC Public Health. 2005;5:119. doi:10.1186/1471-2458-5-119

7. da Rocha Siriano L, Marchiol A, Pereira CM, Cubides J-C, Forsyth C, Augusto de Sousa F. Mandatory notification of chronic Chagas disease: confronting the epidemiological silence in the state of Goías, Brazil. Trop Med Infect Dis. 2020;5:92.

8. WHO. Global distribution of cases of Chagas disease, based on official estimates, 2018. 2021. Available from: www.who.int doc sdefault-sourcentdschagas-2. Accessed January 01, 2021.

9. WHO. Chagas disease (American trypanosomiasis). 2020. Available from: https://www.who.int/health-topics/chagasdisease tab=tab_1. Accessed December 12, 2020.

10. Bern C, Messenger LA, Whitman JD, Maguire JH. Chagas disease in the United States: a public health approach. Clin Microbiol Rev. 2020;33. doi:10.1128/CMR.00023-19

11. Meiser CK, Schaub GA. Xenodiagnosis. In: Mehlhorn H, editor. Parasitology Research Monographs. Vol. 1, Nature Helps ... How Plants and Other Organisms Contribute to Solve Health Problems. Berlin: Springer-Verlag; 2011:273-299.

12. Mehlhorn H, Schaub GA. Chagas' disease, man. In: Mehlhorn H, editor. Encyclopedia of Parasitology. 4th ed. Heidelberg: Springer-Verlag; 2016:479-483

13. Kollien AH, Schaub GA. The development of Trypanosoma cruzi in Triatominae. Parasitol Today. 2000;16:381-387.

14. Balczun C, Siemanowski J, Pausch JK, et al. Intestinal aspartate proteases TiCatD and TiCatD2 of the hematophagous bug Triatoma infestans (Reduviidae): sequence characterisation, expression pattern and characterisation of proteolytic activity. Insect Biochem Mol Biol. 2012;42:240-250.

15. Garcia ES, Genta FA, de Azambuja P, Schaub GA. Interactions between intestinal compounds of triatomines and Trypanosoma cruzi. Trends Parasitol. 2010;26:499-505.

16. Guarneri AA, Schaub GA. Interaction of triatomines, trypanosomes and microbiota. In: Guarneri AA, Lorenzo MG, editors. Triatominae - The Biology of Chagas Disease Vectors. New York: Springer Nature; 2021.

17. Schaub GA, Meiser CK, Balczun C. Interactions of Trypanosoma cruzi and triatomines. In: Mehlhorn H, editor. Parasitology Research Monographs. Vol 2, Progress in Parasitology. Berlin: Springer; 2011:155-178.

18. Messenger LA, Miles MA. Evidence and importance of genetic exchange among field populations of Trypanosoma cruzi. Acta Trop. 2015;151:150-155.

19. Cosentino RO, Agüero F. A simple strain typing assay for Trypanosoma cruzi: discrimination of major evolutionary lineages from a simple amplification product. PLoS Negl Trop Dis. 2012;6 (7):e1777. doi:10.1371/journal.pntd.0001777

20. Fernandes O, Santos SS, Junqueira ACV, et al. Population heterogeneity of Brazilian Trypanosoma cruzi isolates revealed by the mini-exon and ribosomal spacers. Mem Inst Oswaldo Cruz. 1999;94(Suppl. 1):195-197.

21. Cortez MR, Pinho AP, Cuervo P, et al. Trypanosoma cruzi (Kinetoplastida, Trypanosomatidae): ecology of the transmission cycle in the wild environment of the Andean valley of Cochabamba, Bolivia. Exp Parasitol. 2006;114:305-313.

22. Campos-Soto R, Ortiz S, Córdova I, Bruneau N, Botto-Mahan C, Solari A. Interactions between Trypanosoma cruzi the Chagas disease parasite and naturally infected wild Mepraia vectors of Chile. Vector-Borne Zoonotic Dis. 2016;16:165-171.

23. Brenière SF, Waleckx E, Barnabé C. Over six thousand Trypanosoma cruzi strains classified into discrete typing units (DTUs): attempt at an inventory. PLoS Negl Trop Dis. 2016;10 (8):e0004792. doi:10.1371/journal.pntd.0004792 
24. Jansen AM, Roque ALR, Xavier SCC. Trypanosoma cruzi enzootic cycle: general aspects, domestic and synanthropic hosts and reservoirs. In: Telleria J, Tibayrenc M, editors. American Trypanosomiasis Chagas Disease. 2nd ed. London: Elsevier; 2017:265-282.

25. Jansen AM, Xavier SCC, Roque ALR. Ecological aspects of Trypanosoma cruzi: wild hosts and reservoirs. In: Telleria J, Tibayrenc M, editors. American Trypanosomiasis Chagas Disease. 2nd ed. London: Elsevier; 2017:243-264.

26. Lent H, Wygodzinsky P. Revision of the Triatominae (Hemiptera, Reduviidae), and their significance as vectors of Chagas' disease. Bull Am Mus Nat Hist. 1979;163:123-520.

27. WHO. Number of triatominae species identified. 2020. Available from: www.who.int docs ntds chagas-vectors-20200408. Accessed December 12, 2020.

28. Galvão C. Taxonomy. In: Guarneri AA, Lorenzo MG, editors. Triatominae - The Biology of Chagas Disease Vectors. New York: Springer Nature; 2021.

29. Schofield CJ, Galvão C. Classification, evolution, and species groups within the Triatominae. Acta Trop. 2020;110:88-100.

30. Schaub GA, Vogel P, Balczun C. Parasite-vector interactions. In: Walochnik J, Duchêne M, editors. Molecular Parasitology Protozoan Parasites and Their Molecules. Wien: Springer; 2016:431-489.

31. Balczun C, Meiser CK, Schaub GA. Triatomines as vectors of American Trypanosomiasis. In: Mehlhorn H, editor. Parasitology Research Monographs. Vol 3, Arthropods as Vectors of Emerging Diseases. Berlin: Springer-Verlag; 2012:275-299.

32. Schaub GA. Intestinal bacteria/mutualistic symbionts of triatomines - a review. Mitt Dtsch Ges Allg Angew Entomol. 2020;22:191-194.

33. Salcedo-Porras N, Umaña-Diaz $C$, de Bitencourt $O B$, Lowenberger C. The role of bacterial symbionts in triatomines an evolutionary perspective. Microorganisms. 2020;8(9):1438. doi: 10.3390/microorganisms8091438

34. Lazzari CR, Pereira MH, Lorenzo MG. Behavioural biology of Chagas disease vectors. Mem Inst Oswaldo Cruz. 2013;108:34- 47.

35. Ramírez-González MG, Flores-Villegas AL, Salazar-Schettino PM, Gutiérrez-Cabrera AE, Rojas Ortega E, Córdoba-Aguilar A. Zombie bugs? Manipulation of kissing bug behavior by the parasite Trypanosoma cruzi. Acta Trop. 2019;200:105177.

36. Tull T, Henn F, Betz O, Eggs B. Structure and function of the stylets of hematophagous Triatominae (Hemiptera: Reduviidae), with special reference to Dipetalogaster maxima. Arthropod Struct Dev. 2020;58:100952. doi:10.1016/j.asd.2020.100952

37. Ouali R, de Brito K, Salmon D, Bousbata S. High-throughput identification of the Rhodnius prolixus midgut proteome unravels a sophisticated hematophagic machinery. Proteomes. 2020;8 (3):16. doi:10.3390/proteomes 8030016

38. Bauer PG Ultrastrukturelle und physiologische Aspekte des Mitteldarms von Rhodnius prolixus Stal (Insecta; Heteroptera). [Ultrastructural and physiological aspects of the midgut of Rhodnius prolixus Stal (Insecta; Heteroptera)]. [dissertation], Basel: Universität Basel, Switzerland; 1981.

39. Lehane M. Managing the blood meal. In: Lehane M, editor. The Biology of Blood Sucking Insects. 2nd ed. Cambridge: Cambridge University Press; 2005:84-115.

40. Gutiérrez-Cabrera AE, Alejandre-Aguilar R, Hernández-Martínez S, Espinoza B. Development and glycoprotein composition of the perimicrovillar membrane in Triatoma (Meccus) pallidipennis (Hemiptera: Reduviidae). Arthropod Struct Dev. 2014;43(6):571-578.

41. Gutiérrez-Cabrera AE, Córdoba-Aguilar A, Zenteno E, Lowenberger C, Espinoza B. Origin, evolution and function of the hemipteran perimicrovillar membrane with emphasis on Reduviidae that transmit Chagas disease. Bull Entomol Res. 2016;106(3):279-291. doi:10.1017/S0007485315000929
42. Gutiérrez-Cabrera AE, Zandberg WF, Zenteno E, Rodríguez MH, Espinoza B, Lowenberger C. Glycosylation on proteins of the intestine and perimicrovillar membrane of Triatoma (Meccus) pallidipennis, under different feeding conditions. Insect Sci. 2019;26:796-808. doi:10.1111/1744-7917.12579

43. Kollien AH, Waniek PJ, Nisbet AJ, Billingsley PF, Schaub GA. Activity and sequence characterization of two cysteine proteases in the digestive tract of the reduviid bug Triatoma infestans. Insect Mol Biol. 2004;13:569-579.

44. Terra WR, Dias O, Ferreira C. Recruited lysosomal enzymes as major digestive enzymes in insects. Biochem Soc Trans. 2019;47 (2):615-623. doi:10.1042/BST20180344

45. Henriques BS, Gomes B, Oliveira PL, et al. Characterization of the temporal pattern of blood protein digestion in Rhodnius prolixus: first description of early and late gut cathepsins. Front Physiol. 2021;11:509310. doi:10.3389/fphys.2020.509310

46. Henriques BS, Gomes B, da Costa SG, et al. Genome wide mapping of peptidases in Rhodnius prolixus: identification of protease gene duplications, horizontally transferred proteases and analysis of peptidase A1 structures, with considerations on their role in the evolution of hematophagy in Triatominae. Front Physiol. 2017;8:1051. doi:10.3389/fphys.2017.01051

47. Walter-Nuno AB, Taracena ML, Mesquita RD. Silencing of iron and heme-related genes revealed a paramount role of iron in the physiology of the hematophagous vector Rhodnius prolixus. Front Genet. 2018;9:19. doi:10.3389/fgene.2018.00019

48. Sterkel M, Oliveira PL. Developmental roles of tyrosine metabolism enzymes in the blood-sucking insect Rhodnius prolixus. Proc Roy Soc B. 2016;284. doi:10.1098/rspb.2016.2607

49. Antunes LCM, Han J, Pan J. Metabolic signatures of triatomine vectors of Trypanosoma cruzi unveiled by metabolomics. PLoS One. 2013;8(10):e77283.

50. Pausch JK, Balczun C, Schaub GA. Interactions of Trypanosoma cruzi, the etiologic agent of Chagas disease, and triatomines (Reduviidae). Mitt Dtsch Ges Allg Angew Entomol. 2012;18:289-296.

51. Kollien AH, Grospietsch T, Kleffmann T, Zerbst-Boroffka I, Schaub GA. Ionic composition of the rectal contents and excreta of the reduviid bug Triatoma infestans. $J$ Insect Physiol. 2001;47:739-747.

52. Müller U, Vogel P, Alber G, Schaub GA. The innate immune system of mammals and insects. In: Egesten A, Schmidt A, Herwald H, editors. Contributions to Microbiology. Vol. 15. Basel: Karger; 2008:21-44.

53. Salcedo-Porras N, Lowenberger C. The innate immune system of kissing bugs, vectors of Chagas disease. Dev Comp Immunol. 2019;98:119-128. doi:10.1016/j.dci.2019.04.007

54. Salcedo-Porras N, Lowenberger C. The immune system of triatomines. In: Guarneri AA, Lorenzo MG, editors. Triatominae - The Biology of Chagas Disease Vectors. New York: Springer Nature; 2021.

55. Hinestroza G, Ortiz MI, Molina J. Behavioral fever response in Rhodnius prolixus (Reduviidae: Triatominae) to intracoelomic inoculation of Trypanosoma cruzi. Rev Soc Bras Med Trop. 2016;49:425-432.

56. Flores-Villegas AL, Salazar-Schettino PM, Córdoba-Aguilar A, et al. Immune defence mechanisms of triatomines against bacteria, viruses, fungi and parasites. Bull Entomol Res. 2015;105:523-532.

57. Gumiel M, Passos de Mattos D, Vieira CS, et al. Proteome of the triatomine digestive tract: from catalytic to immune pathways; focusing on annexin expression. Front Mol Biosci. 2020;7:589435. doi:10.3389/fmolb.2020.589435

58. Salcedo-Porras N, Guarneri A, Oliveira PL, Lowenberger C. Rhodnius prolixus: identification of missing components of the IMD immune signaling pathway and functional characterization of its role in eliminating bacteria. PLoS One. 2019;14(4): e0214794. doi:10.1371/journal.pone.0214794 
59. Salcedo-Porras N, Noor S, Cai C, Oliveira PL, Lowenberger C. Rhodnius prolixus uses the peptidoglycan recognition receptor rpPGRP-LC/LA to detect Gram-negative bacteria and activate the IMD pathway. Curr Res Insect Sci. 2021;1:100006.

60. Díaz-Garrido P, Sepúlveda-Robles O, Martínez-Martínez I, Espinoza B. Variability of defensin genes from a Mexican endemic Triatominae: Triatoma (Meccus) pallidipennis (Hemiptera: Reduviidae). Biosci Rep. 2018;38(5):BSR20180988.

61. Meiser CK Bacteriolytic and anticoagulant proteins in the saliva and intestine of blood sucking bugs (Triatominae, Insecta). [dissertation]. Bochum: Ruhr-University; 2009.

62. Kollien AH, Fechner S, Waniek PJ, Schaub GA. Isolation and characterization of a cDNA encoding for a lysozyme from the gut of the reduviid bug Triatoma infestans. Arch Insect Biochem Physiol. 2003;53:134-145.

63. Araújo CAC, Waniek PJ, Stock P, Mayer C, Jansen AM, Schaub GA. Sequence characterization and expression patterns of defensin and lysozyme encoding genes from the gut of the reduviid bug Triatoma brasiliensis. Insect Biochem Mol Biol. 2006;36:547-560.

64. González-Rete B, Salazar-Schettino PM, Bucio-Torres MI, Córdoba-Aguilar A, Cabrera-Bravo M. Activity of the prophenoloxidase system and survival of triatomines infected with different Trypanosoma cruzi strains under different temperatures: understanding Chagas disease in the face of climate change. Parasit Vectors. 2019;12(1):219.

65. Meiser CK, Piechura H, Werner T, et al. Kazal-type inhibitors in the stomach of Panstrongylus megistus (Triatominae, Reduviidae). Insect Biochem Mol Biol. 2010;40:345-353.

66. Lima MS, Silva Laport MS, Seixas Lorosa ES. Bacterial community composition in the salivary glands of triatomines (Hemiptera: Reduviidae). PLoS Negl Trop Dis. 2018;12(9):e0006739.

67. Amino R, Martins RM, Procopio J, Hirata IY, Juliano MA, Schenkman S. Trialysin, a novel pore-forming protein from saliva of hematophagous insects activated by limited proteolysis. J Biol Chem. 2002;277:6207-6213.

68. Kulkarni MM, Karafova A, Kamysz W, Schenkman S, Pelle R, McGwire BS. Secreted trypanosome cyclophilin inactivates lytic insect defense peptides and induces parasite calcineurin activation and infectivity. $J$ Biol Chem. 2013;288:8772-8784.

69. Azambuja P, Garcia ES, Waniek PJ, et al. Rhodnius prolixus: from physiology by Wigglesworth to recent studies of immune system modulation by Trypanosoma cruzi and Trypanosoma rangeli. J Insect Physiol. 2017;97:45-65.

70. Dias E. Estudos sobre o Schizotrypanum cruzi [Studies on Schizotrypanum cruzi]. Mem Inst Oswaldo Cruz. 1934;28:1-110.

71. Brener Z. A new aspect of Trypanosoma cruzi life-cycle in the invertebrate host. J Protozool. 1972;19:23-27.

72. Kessler RL, Contreras VT, Marliére NP, et al. Recently differentiated epimastigotes from Trypanosoma cruzi are infective to the mammalian host. Mol Microbiol. 2017;104:712-736.

73. Dias F de A, Guerra B, Vieira LR, et al. Monitoring of the parasite load in the digestive tract of Rhodnius prolixus by combined qPCR analysis and imaging techniques provides new insights into the trypanosome life cycle. PLoS Negl Trop Dis. 2015;9(10):e0004186.

74. Ferreira RC, Kessler RL, Lorenzo MG, et al. Colonization of Rhodnius prolixus gut by Trypanosoma cruzi involves an extensive parasite killing. Parasitology. 2016;143:434-443.

75. Schaub GA. Direct transmission of Trypanosoma cruzi between vectors of Chagas' disease. Acta Trop. 1988;45:11-19.

76. Schaub GA. Trypanosoma cruzi: quantitative studies of development of two strains in small intestine and rectum of the vector Triatoma infestans. Exp Parasitol. 1989;68:260-273.

77. Gonzalez MS, Nogueira NFS, Mello CB, et al. Influence of brain and azadirachtin on Trypanosoma cruzi development in the vector Rhodnius prolixus. Exp Parasitol. 1999;92:100-108.
78. Gonzalez MS, Hamedi A, Albuquerque-Cunha JM, et al. Antiserum against perimicrovillar membranes and midgut tissue reduces the development of Trypanosoma cruzi in the insect vector, Rhodnius prolixus. Exp Parasitol. 2006;114:297-304.

79. Cortez MR, Provençano AF, Silva CE, et al. Trypanosoma cruzi: effects of azadirachtin and ecdysone on the dynamic development in Rhodnius prolixus larvae. Exp Parasitol. 2012;131:363-371.

80. Nogueira NF, Gonzalez MS, Gomes JE, et al. Trypanosoma cruzi: involvement of glycoinositolphospholipids in the attachment to the luminal midgut surface of Rhodnius prolixus. Exp Parasitol. 2007;116:120-128.

81. Ennes-Vidal V, Menna-Barreto R, Santos ALS, Branquinha MH. d'Avila-Levy CM. MDL28170, a calpain inhibitor, affects Trypanosoma cruzi metacyclogenesis, ultrastructure and attachment to Rhodnius prolixus midgut. PLoS One. 2011;6(4):e18371.

82. Oliveira FOR, Alves CR, Souza-Silva F, et al. Trypanosoma cruzi heparin-binding proteins mediate the adherence of epimastigotes to the midgut epithelial cells of Rhodnius prolixus. Parasitology. 2012;139:735-743.

83. Uehara LA, Moreira OC, Oliveira AC. Cruzipain promotes Trypanosoma cruzi adhesion to Rhodnius prolixus midgut. PLoS Negl Trop Dis. 2012;6(12):e1958.

84. Zimmermann D, Peters W, Schaub GA. Differences in binding of lectin-gold conjugates by Trypanosoma cruzi and Blastocrithidia triatomae (Trypanosomatidae) in the intestine of Triatoma infestans (Reduviidae). Parasitol Res. 1987;74:5-10.

85. de Cámara MLM, Balouz V, Cameán Centeno C, et al. Trypanosoma cruzi surface mucins are involved in the attachment to the Triatoma infestans rectal ampoule. PLoS Negl Trop Dis. 2019;13(5):e0007418.

86. Kleffmann $\mathrm{T}$ Mechanismen der Anheftung und Induktion der Metazyklogenese von Trypanosoma cruzi in Triatoma infestans [Mechanisms of attachment and induction of metacycylogenesis of Trypanosoma cruzi in Triatoma infestans]. [dissertation]. Bochum: Ruhr-University; 1999.

87. Tamayo LD, Guhl F, Vallejo GA, Ramírez JD. The effect of temperature increase on the development of Rhodnius prolixus and the course of Trypanosoma cruzi metacyclogenesis. PLoS Negl Trop Dis. 2018;12(8):e0006735.

88. Kollien AH, Schaub GA. Trypanosoma cruzi in the rectum of the bug Triatoma infestans: effects of blood ingestion by the starved vector. Am J Trop Med Hyg. 1998;59:166-170.

89. Kollien AH, Schaub GA. The development of Trypanosoma cruzi (Trypanosomatidae) in the reduviid bug Triatoma infestans (Insecta): influence of starvation. J Euk Microbiol. 1998;45:59-63.

90. Schaub GA. Interactions of trypanosomatids and triatomines. $A d v$ Insect Physiol. 2009;37:177-242.

91. Schaub GA. Does Trypanosoma cruzi stress its vector? Parasitol Today. 1989;5:185-188.

92. Peterson JK, Graham AL, Dobson AP, Chavez OT. Rhodnius prolixus life history outcomes differ when infected with different Trypanosoma cruzi I strains. Am J Trop Med Hyg. 2015;93:564-572.

93. Cordero-Montoya G, Flores-Villegas AL, Salazar-Schettino PM, et al. The cost of being a killer's accomplice: Trypanosoma cruzi impairs the fitness of kissing bugs. Parasitol Res. 2019;118:2523-2529.

94. Vallejo GA, Guhl F, Schaub GA. Triatominae - Trypanosoma cruzi/T rangeli: vector-parasite interactions. Acta Trop. 2009;110:137-147.

95. de Fuentes-Vicente JA, Gutiérrez-Cabrera AE, Flores-Villegas AL. What makes an effective Chagas disease vector? Factors underlying Trypanosoma cruzi-triatomine interactions. Acta Trop. 2018;183:23-31.

96. Córdoba-Aguilar A. Chagas bugs and Trypanosoma cruzi: puppets and puppeteer? Acta Trop. 2020;211:105600. doi:10.1016/j. actatropica.2020.105600 
97. Schaub GA. The effect of Blastocrithidia triatomae (Trypanosomatidae) on the reduviid bug Triatoma infestans: influence of group size. J Invertebr Pathol. 1990;56:249-257.

98. Eichler S. Interaktionen von Triatominen mit ihren Symbionten und Trypanosomatiden [Interactions of triatomines, symbionts and trypanosomatids]. [dissertation]. Bochum: Ruhr-University; 1998.

99. Guarneri AA, Pereira MH, Diotaiuti L. Influence of the blood meal source on the development of Triatoma infestans, Triatoma brasiliensis, Triatoma sordida and Triatoma pseudomaculata (Heteroptera, Reduviidae). J Med Entomol. 2000;37:373-379.

100. Heger TJ, Guerin PM, Eugster W. Microclimatic factors influencing refugium suitability for Rhodnius prolixus. Physiol Entomol. 2006;31(3):248-256. doi:10.1111/j.1365-3032.2006.00514.x

101. Rolandi C, Schilman PE. The costs of living in a thermal fluctuating environment for the tropical haematophagous bug, Rhodnius prolixus. $J$ Thermal Biol. 2018;74:92-99. doi:10.1016/j. jtherbio.2018.03.022

102. Schofield CJ. The behaviour of Triatominae (Hemiptera: Reduviidae): a review. Bull Entomol Res. 1979;69(3):363-379. doi:10.1017/S0007485300018897

103. Takano-Lee M, Edman JD. Lack of manipulation of Rhodnius prolixus (Hemiptera: Reduviidae) vector competence by Trypanosoma cruzi. J Med Entomol. 2002;39(1):44-51. doi:10.1603/0022-2585-39.1.44

104. Verly T, Costa S, Lima N, et al. Vector competence and feeding-excretion behavior of Triatoma rubrovaria (Blanchard, 1843) (Hemiptera: Reduviidae) infected with Trypanosoma cruzi TcVI. PLoS Negl Trop Dis. 2020;14(9):e0008712.

105. Botto-Mahan C, Cattan PE, Medel R. Chagas disease parasite induces behavioural changes in the kissing bug Mepraia spinolai. Acta Trop. 2006;98:219-223.

106. Pereyra N, Lobbia PA, Mougabure-Cueto G. Effects of the infection with Trypanosoma cruzi on the feeding and excretion/defecation patterns of Triatoma infestans. Bull Entomol Res. 2020;110:169-176.

107. Reisenman CE, Gregory T, Guerenstein PG, Hildebrand JG. Feeding and defecation behavior of Triatoma rubida (Uhler, 1894) (Hemiptera: Reduviidae) under laboratory conditions, and its potential role as a vector of Chagas disease in Arizona, USA. Am Soc Trop Med Hyg. 2011;85:648-656.

108. Estay-Olea D, Correa JP, de Bona S, et al. Trypanosoma cruzi could affect wild triatomine approaching behaviour to humans by altering vector nutritional status: a field test. Acta Trop. 2020;3:105574.

109. Marliére NP, Latorre-Estivalis JM, Lorenzo MG, et al. Trypanosomes modify the behavior of their insect hosts: effects on locomotion and on the expression of a related gene. PLoS Negl Trop Dis. 2015;9(8):e0003973.

110. Castro LA, Peterson JK, Saldana A, et al. Flight behavior and performance of Rhodnius pallescens (Hemiptera: Reduviidae) on a tethered flight mill. J Med Entomol. 2014;51:1010-1018.

111. Nouvellet P, Ramirez-Sierra MJ, Dumonteil E, Gourbière S. Effects of genetic factors and infection status on wing morphology of Triatoma dimidiata species complex in the Yucatán peninsula, Mexico. Infect Genet Evol. 2011;11:1243-1249.

112. Ramirez-Sierra MJ, Herrera-Aguilar $\mathrm{M}$, Gourbière $\mathrm{S}$, Dumonteil E. Patterns of house infestation dynamic by non-domiciliated Triatoma dimidiata reveal a spatial gradient of infestation in rural villages and potential insect manipulation by Trypanosoma cruzi. Trop Med Int Health. 2010;15:77-86.

113. Lehane MJ, McEwen PK, Whitaker CJ, Schofield CJ. The role of temperature and nutritional status in flight initiation by Triatoma infestans. Acta Trop. 1992;52:27-38.

114. Depickère S, Ramírez-Ávila GM, Deneubourg J-L. Alteration of the aggregation and spatial organization of the vector of Chagas disease, Triatoma infestans, by the parasite Trypanosoma cruzi. Sci Rep. 2019;9:17432.
115. Villalobos G, Nava-Bolaños A, De Fuentes-Vicente JA, et al. A reduction in ecological niche for Trypanosoma cruzi-infected triatomine bugs. Parasit Vectors. 2019;12:240.

116. Reis dos Santos J, Lacombe D. Estudos relativos à duraçao da ecdise e ovoposiçao de Triatoma infestans infectado pelo Trypanosoma cruzi. An Acad Brasil Ciênc. 1985;57:127.

117. Botto-Mahan C, Ossa CG, Medel R. Direct and indirect pathway of fitness-impact in a protozoan-infected kissing bug. Physiol Entomol. 2008;33:25-30.

118. Botto-Mahan C. Trypanosoma cruzi induces life-history trait changes in the wild kissing bug Mepraia spinolai: implications for parasite transmission. Vector-Borne Zoonotic Dis. 2009;9:505-510.

119. Oliveira TG, Carvalho-Costa FA, Gomes TF, Sarquis O, Sposina R, Lima MM. Developmental and reproductive patterns of Triatoma brasiliensis infected with Trypanosoma cruzi under laboratory conditions. Mem Inst Oswaldo Cruz. 2010;105:1057-1060.

120. Juarez E. Observações sobre o ciclo evolutivo do Triatoma infestans, em condições de laboratório (Hemiptera, Reduviidae). Rev Saude Publ. 1970;4:147-166.

121. Schaub GA. Development of isolated and group-reared first instars of Triatoma infestans infected with Trypanosoma cruzi. Parasitol Res. 1988;74:593-594.

122. Schaub GA. Developmental time and mortality of larvae of Triatoma infestans infected with Trypanosoma cruzi. Trans $R$ Soc Trop Med Hyg. 1988;82:94-97.

123. Lima MM, Borges-Pereira J, Albuquerque Dos Santos JA, Teixeira Pinto Z, Vianna Braga M. Teixeira Pinto Z, Vianna Braga M. Development and reproduction of Panstrongylus megistus (Hemiptera: Reduviidae) infected with Trypanosoma cruzi, under laboratory conditions. Ann Entomol Soc Am. 1992;85:458-461.

124. Elliot SL, Rodrigues JDO, Lorenzo MG, Martins-Filho OA, Guarneri AA. Trypanosoma cruzi, etiological agent of Chagas disease, is virulent to its triatomine vector Rhodnius prolixus in a temperature-dependent manner. PLoS Negl Trop Dis. 2015;9(3): e0003646.

125. Noireau F, Dujardin JP. Flight and nutritional status of sylvatic Triatoma sordida and Triatoma guasayana. Mem Inst Oswaldo Cruz. 2001;96:385-389.

126. Sarquis O, Carvalho-Costa FA, Oliveira LS, et al. Ecology of Triatoma brasiliensis in northeastern Brazil: seasonal distribution, feeding resources, and Trypanosoma cruzi infection in a sylvatic population. J Vector Ecol. 2010;35:385-394.

127. Mc Cabe A, Yañez F, Pinto R, et al. Survivorship of wild caught Mepraia spinolai nymphs: the effect of seasonality and Trypanosoma cruzi infection after feeding and fasting in the laboratory. Infect Genet Evol. 2019;71:197-204.

128. Schaub GA, Lösch P. Parasite/host-interrelationships of the trypanosomatids Trypanosoma cruzi and Blastocrithidia triatomae and the reduviid bug Triatoma infestans: influence of starvation of the bug. Ann Trop Med Parasitol. 1989;83:215-223.

129. Botto-Mahan C, Campos V, Medel R. Sex-dependent infection causes nonadditive effects on kissing bug fecundity. Ecol Evol. 2017;7:3552-3557.

130. Schaub GA, Meiser A, Böker C (1985) The influence of the trypanosomatids Blastocrithidia triatomae or Trypanosoma cruzi on reproduction of Triatoma infestans (Reduviidae). Lecture presented at: VII. International Congress of Protozoology; June 2229; 1985. Nairobi, Kenya: 83.

131. Fellet MR, Lorenzo MG, Elliot SL, Carrasco D, Guarneri AA. Effects of infection by Trypanosoma cruzi and Trypanosoma rangeli on the reproductive performance of the vector Rhodnius prolixus. PLoS One. 2014;9(8):e105255.

132. Oliveira ABB, Tedeschi BBB, de Oliveira J, et al. Parasite $\times$ vector relationship in Chagas disease: does Trypanosoma cruzi (Chagas, 1909) infection affect the spermatogenesis of Triatoma infestans (Klug, 1834)? Parasitol Res. 2020;119:1-6. 
133. Peterson JK, Graham AL, Elliot RJ, Dobson AP, Chavez OT. Trypanosoma cruzi-Trypanosoma rangeli co-infection ameliorates negative effects of single trypanosome infections in experimentally infected Rhodnius prolixus. Parasitology. 2016;143:1157-1167.

134. Carcavallo RU. Epidemiologia de la trypanosomiasis Americana $\mathrm{y}$ las posibilidades del control biologico [Epidemiology of American Trypanosomiasis and the possibilities of biological control]. In: Singh KS, Tandan BK, editors. H. D. Srivastava Commemoration Volume. Izatnagar: Indian Veterinary Research Institute; 1970:381-390.

135. Neves D, Peres R. Aspectos da biologia do Rhodnius prolixus quando alimentado em animais sadios ou infectados com o Trypanosoma cruzi. Rev Bras Biol. 1975;35:317-320.

136. Zeledón R, Guardia VM, Zúñiga A, Swartzwelder JC. Biology and ethology of Triatoma dimidiata (Latreille, 1811). II. Life span of adults and fecundity and fertility of females. $J$ Med Entomol. 1970;7:462-469.

137. Pausch JK Characterization of intestinal antibacterial factors of Triatoma infestans (Reduviidae, Insecta) and their interaction with Trypanosoma cruzi (Trypanosomatidae, Kinetoplastida). [dissertation]. Bochum: Ruhr-University; 2012.

138. Mucci J, Lantos AB, Buscaglia CA, Leguizamón MS, Campetella O. The Trypanosoma cruzi surface, a nanoscale patchwork quilt. Trends Parasitol. 2017;32:102-112.

139. Hölscher C, Mossmann H, Hartmann R, Schaub GA. Effects of the isolation methodology on protein profiles of blood trypomastigotes of Trypanosoma cruzi. Parasitology. 2003;126:41-51.

140. Ursic-Bedoya RJ, Nazzari H, Cooper D, Triana O, Wolff M, Lowenberger C. Identification and characterization of two novel lysozymes from Rhodnius prolixus, a vector of Chagas disease. $J$ Insect Physiol. 2008;54:593-603.

141. Waniek PJ, Jansen AM, Araújo CAC. Trypanosoma cruzi infection modulates the expression of Triatoma brasiliensis def1 in the midgut. Vector-Borne Zoonotic Dis. 2011;11:845-847.

142. Buarque DS, Braz GRC, Martins RM, et al. Differential expression profiles in the midgut of Triatoma infestans infected with Trypanosoma cruzi. PLoS One. 2013;8(5):e61203.

143. Borges EC, Machado EMM, Garcia ES, Azambuja P. Trypanosoma cruzi: effects of infection on cathepsin D activity in the midgut of Rhodnius prolixus. Exp Parasitol. 2006;112:130-133.

144. Buarque DS, Spindola LM, Martins RM, Braz GR, Tanaka AS. Tigutcystatin, a cysteine protease inhibitor from Triatoma infestans midgut expressed in response to Trypanosoma cruzi. Biochem Biophys Res Comm. 2011;413:241-247.

145. Whitten M, Sun F, Tew I, et al. Differential modulation of Rhodnius prolixus nitric oxide activities following challenge with Trypanosoma rangeli, T. cruzi and bacterial cell wall components. Insect Biochem Mol Biol. 2007;37:440-452.

146. Favila-Ruiz G, Jiménez-Cortés JG, Córdoba-Aguilar A, et al. Effects of Trypanosoma cruzi on the phenoloxidase and prophenoloxidase activity in the vector Meccus pallidipennis (Hemiptera: Reduviidae). Parasit Vectors. 2018;11:434. doi:10.1186/s13071018-3016-0
147. Castro DP, Moraes CS, Gonzalez MS, Ratcliffe NA, Azambuja P, Garcia ES. Trypanosoma cruzi immune response modulation decreases microbiota in Rhodnius prolixus gut and is crucial for parasite survival and development. PLoS One. 2012;7(5):e36591. doi:10.1371/journal.pone.0036591

148. Soares TS, Buarque DS, Queiroz BR, et al. A Kazal-type inhibitor is modulated by Trypanosoma cruzi to control microbiota inside the anterior midgut of Rhodnius prolixus. Biochimie. 2015;112:41-48.

149. Buarque DS, Gomes CM, Araújo RN, et al. A new antimicrobial protein from the anterior midgut of Triatoma infestans mediates Trypanosoma cruzi establishment by controlling the microbiota. Biochimie. 2016;123:138-143.

150. Vieira CS, Moreira OC, Batista KKS, Ratcliffe NA, Castro DP, Azambuja P. The NF- $\mathrm{KB}$ inhibitor, IMD-0354, affects immune gene expression, bacterial microbiota and Trypanosoma cruzi infection in Rhodnius prolixus midgut. Front Physiol. 2018;9:1189. doi:10.3389/fphys.2018.01189

151. Vieira CS, Waniek PJ, Castro DP, Mattos DP, Moreira OC, Azambuja P. Impact of Trypanosoma cruzi on antimicrobial peptide gene expression and activity in the fat body and midgut of Rhodnius prolixus. Parasit Vectors. 2016;9:119.

152. de Fuentes-Vicente JA, Vidal-López DG, Flores-Villegas AL. Trypanosoma cruzi: a review of biological and methodological factors in Mexican strains. Acta Trop. 2019;195:51-57.

153. Tobias NJ, Eberhard FE, Guarneri AA. Enzymatic biosynthesis of B-complex vitamins is supplied by diverse microbiota in the Rhodnius prolixus anterior midgut following Trypanosoma cruzi infection. Comput Struct Biotechnol J. 2020;18:3395-3401.

154. Hamedi A, Botelho L, Britto C, et al. In vitro metacyclogenesis of Trypanosoma cruzi induced by starvation correlates with a transient adenylyl cyclase stimulation as well as with a constitutive upregulation of adenylyl cyclase expression. $\mathrm{Mol}$ Biochem Parasitol. 2015;200:9-18.

155. Pachebat JA, van Keulen G, Whitten MM, et al. Draft genome sequence of Rhodococcus rhodnii strain LMG5362, a symbiont of Rhodnius prolixus (Hemiptera, Reduviidae, Triatominae), the principle vector of Trypanosoma cruzi. Genome Announc. 2013;1(3): e00329-13.

156. Ribeiro JMC, Genta FA, Sorgine MHF, et al. An insight into the transcriptome of the digestive tract of the bloodsucking bug, Rhodnius prolixus. PLoS Negl Trop Dis. 2014;8(1):e2594.

157. Avila CC, Mule SN, Rosa-Fernandes L, et al. Proteome-wide analysis of Trypanosoma cruzi exponential and stationary growth phases reveals a subcellular compartment-specific regulation. Genes. 2018;9(8):413. doi:10.3390/genes9080413

158. Liu Q, Guo Y, Zhang Y, et al. A chromosomal-level genome assembly for the insect vector for Chagas disease, Triatoma rubrofasciata. GigaSci. 2019;8:giz089. doi:10.1093/gigascience/giz089

159. Ouali R, Vieira LR, Salmon D, Bousbata S. Early post-prandial regulation of protein expression in the midgut of Chagas disease vector Rhodnius prolixus highlights new potential targets for vector control strategy. Microorganisms. 2021;9(4):804. doi:10.3390/microorganisms 9040804

\section{Publish your work in this journal}

Research and Reports in Tropical Medicine is an international, peerreviewed, open access journal publishing original research, case reports, editorials, reviews and commentaries on all areas of tropical medicine, including: Diseases and medicine in tropical regions; Entomology; Epidemiology; Health economics issues; Infectious disease; Laboratory science and new technology in tropical medicine;

Parasitology; Public health medicine/health care policy in tropical regions; and Microbiology. The manuscript management system is completely online and includes a very quick and fair peer-review system. Visit http://www.dovepress.com/testimonials.php to read real quotes from published authors. 